\title{
Patient-Centered Communication and Diagnostic Testing
}

\author{
Ronald M. Epstein, $M D^{1,2,3}$ \\ Peter Franks, $M D^{4}$ \\ Cleveland G. Shields, $P b D^{1,2,3}$ \\ Sean C. Meldrum, MS ${ }^{1,3}$ \\ Katherine N. Miller, BS $S^{1,3}$ \\ Thomas L. Campbell, $M D^{1,2,3}$ \\ Kevin Fiscella, MD, MPH ${ }^{1,3,5}$ \\ 'Department of Family Medicine, University \\ of Rochester Medical Center, Rochester, NY \\ ${ }^{2}$ Department of Psychiatry, University of \\ Rochester Medical Center, Rochester, NY \\ ${ }^{3}$ Rochester Center to Improve Communica- \\ tion in Health Care, Rochester, NY \\ ${ }^{4}$ Department of Family and Community \\ Medicine, and Center for Health Services \\ Research in Primary Care, University of \\ California, Davis, Sacramento Campus, \\ Sacramento, Calif \\ ${ }^{5}$ Department of Community and \\ Preventive Medicine, University of \\ Rochester, Rochester, NY
}

Conflicts of interest: none reported

\section{CORRESPONDING AUTHOR}

Ronald M. Epstein, MD

1381 South Avenue

Rochester, NY 14620

Ronald_Epstein@urmc.rochester.edu

\begin{abstract}
PURPOSE Although patient-centered communication is associated with improved health and patient trust, information about the impact of patient-centered communication on health care costs is limited. We studied the relationship between patient-centered communication and diagnostic testing expenditures.
\end{abstract}

METHODS We undertook an observational cross-sectional study using covert standardized patient visits to study physician interaction style and its relationship to diagnostic testing costs. Participants were 100 primary care physicians in the Rochester, NY, area participating in a large managed care organization (MCO). Audio recordings of 2 standardized patient encounters for each physician were rated using the Measure of Patient-Centered Communication (MPCC). Standardized diagnostic testing and other expenditures, adjusted for patient demographics and case-mix, were derived from the MCO claims database. Analyses were adjusted for demographics and standardized patient detection.

RESULTS Compared with other physicians, those who had MPCC scores in the lowest tercile had greater standardized diagnostic testing expenditures $111.0 \%$ higher, 95\% confidence interval $[\mathrm{Cl}], 4.5 \%-17.8 \%)$ and greater total standardized expenditures (3.5\% higher, 95\% Cl, 1.0\%-6.1\%). Whereas lower MPCC scores were associated with shorter visits, adjustment for visit length and standardized patient detection did not affect the relationship with expenditures. Total (testing, ambulatory and hospital care) expenditures were also greater for physicians who had lower MPCC scores, an effect primarily associated with the effect on testing expenditures.

CONCLUSIONS Patient-centered communication is associated with fewer diagnostic testing expenditures but also with increased visit length. Because costs and visit length may affect physicians' and health systems' willingness to endorse and practice a patient-centered approach, these results should be confirmed in future randomized trials.

Ann Fam Med 2005;3:415-421. DOI: 10.1370/afm.348.

\section{INTRODUCTION}

$\mathrm{P}$ atient-centered communication is based on a moral philosophy that calls for physicians to expand upon the biomedical approach to care by (1) helping patients feel understood through inquiry into patients'

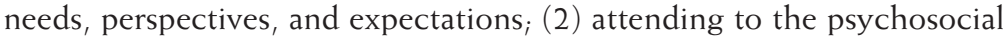
context; and (3) expanding patients' involvement in understanding their illnesses and in decisions that affect their health. ${ }^{1-3}$ Patient-centered communication is a complex construct, aspects of which have differential associations with such outcomes as patient satisfaction ${ }^{4}$ and control of chronic disease. ${ }^{5-8}$ Most physicians tend to use a biomedical rather than a patientcentered communication style, ${ }^{9}$ whereas most patients prefer a patient-centered approach. ${ }^{10,11}$

Although patient-centered communication should not be advocated on the basis of cost considerations alone, it is important to understand the cost implications of such an approach from a health policy perspec- 
tive. Concerns that patient-centered communication might drive up health care costs has led to at least 2 inquiries into the relationship between communication and diagnostic testing. ${ }^{12,13}$ Even though both studies reported that elements of patient-centered communication are associated with fewer diagnostic tests, these studies have been limited by several factors. Stewart et $\mathrm{al}_{,}{ }^{12}$ in their study of 39 family physicians and 315 of their patients, found that 1 of 3 components of a newly developed patient survey of "perceived patientcenteredness" was associated with reduced diagnostic testing ${ }_{i}$ component of their validated observational measure was related to the survey measure but not to other outcomes. Reliance on the same patients to yield effects on both diagnostic testing and measures of patient-centered communication, however, may have introduced biases ${ }^{14}$; for example, severity of illness is associated both with lower patient ratings of their physicians ${ }^{15}$ and with increased testing. The level of analysis was at the level of the individual encounter, precluding an overall measure of a particular physician's style of communication and use of diagnostic tests independent of each patient's influence on patient-centered communication. ${ }^{16}$

Bertakis et $\mathrm{al}^{13}$ randomized 509 new patients to primary care resident physicians and measured these physicians' interaction style and the costs generated by the patients for a 1-year period. Although Bertakis et al did not study patient-centered communication as such, a "technically oriented" visit style was associated with more diagnostic tests than was a style characterized by patient activation

Patient-centered theory suggests that patients who think they understand their symptoms and feel understood by their physicians may be less anxious, have greater confidence in their physician's abilities, and be more trusting of their physician. ${ }^{1-3}$ A previous report from the data presented here suggests that physicians who exhibit more observable patient-centered communication behaviors also generate higher levels of trust, not only in the observed standardized patients but overall. ${ }^{17}$ Patients who trust their physicians' judgment may be less likely to demand diagnostic tests in a quest for certainty or sense of control. ${ }^{18}$ Similarly, mutual understanding and trust may decrease the drive to order diagnostic tests in an effort to allay the physician's own anxiety and fear of litigation. Given that diagnostic test costs are under physician control more than are inpatient costs (which are driven by diagnostic related groups), the former would likely be more sensitive to physician communication style.

Ideally, reduced testing should occur in situations in which diagnostic testing is of unproved benefit and in which reduced testing does not reduce patient satisfac- tion. ${ }^{19}$ Among patients with back pain, for example, Deyo $^{20}$ found that patients who reported their physicians gave "adequate explanation" of their symptoms also demanded fewer diagnostic tests and were as satisfied as those who received tests. Thus, in the original study design, we sought to compare physicians' behavior when evaluating conditions that were medically straightforward (such as gastroesophageal reflux disease [GERD]) with their behavior when evaluating medically unexplained symptoms (atypical chest pain) likely to increase anxiety and drive a need for certainty. We report here the aggregate effect of patient-centered communication on costs; comparisons between the 2 conditions and visit-specific outcomes will be reported elsewhere.

A key challenge to studying the relationship between patient-centered communication and diagnostic test use is adequately controlling for patient factors, including type of visit, illness severity, number of concerns, stated preferences, and choice of physician based on practice style. Because it is difficult to adjust adequately for these differences among patients, observed effects may simply reflect confounding by patient factors. Furthermore, no study has examined whether patient-centeredness represents, in part, a physician's style, observable for more than 1 patient interaction, or whether that style exhibits any relation to the use of diagnostic testing and visit length.

To address these limitations, we measured the physicians' communication style using unannounced covert standardized patients who carried concealed audio recorders. Standardized patients have been used to generate reliable estimates of health care processes ${ }^{21}$; these estimates have been found to correspond to actual physician behavior more accurately than chart audit or response to vignettes. ${ }^{22} \mathrm{~A}$ focus group with community physicians in preparation for this study suggested that we could achieve the required number of physicians for adequate statistical power if we used no more than 2 standardized patient visits per physician. To assess costs, we used standardized expenditures generated by those same physicians with their real patients for a 1-year period derived from a managed care claims database.

\section{METHODS}

The study used patient surveys and audio recordings of clinical encounters with standardized patients to arrive at descriptions of physicians' overall clinical style. Claims data from a large managed care organization (MCO) were used to assess diagnostic testing costs. ${ }^{30}$ These expenditures were considered more representative of the clinician's overall diagnostic test use patterns than were single standardized patient visits. 


\section{Physician Sample}

In late 1999, we identified 594 primary care physicians in active clinical practice within 45 minutes of Rochester, NY, belonging to a large MCO serving the 8county Rochester, NY, region (population 1.1 million). To achieve stable measures of costs, only the 506 physicians who had more than 100 patients in the MCO were eligible; thus, enrolled physicians, compared with physicians not enrolled, had larger practices. We also intentionally oversampled family physicians to allow for comparisons between family physicians and internists (reported elsewhere). A maximum of 2 physicians per practice were recruited to avoid clustering effects and to minimize physician detection of standardized patients. The remaining 297 eligible physicians were recruited by 12 physician-recruiters in random order until a total of 100 physicians were recruited. Physicians gave informed consent to participate in a study of "patient care and outcomes." They agreed to have 2 unannounced, covert, surreptitiously audio recorded standardized patient visits at any point in the subsequent 12 months during 2000-2001. Physicians were reimbursed $\$ 100$ for each standardized patient visit (slightly less than usual charges for a new patient appointment for acute care) and received $\$ 100$ for completing the survey instruments; $\$ 100$ was provided to the office staff at each site for their help with scheduling standardized patient visits, facilitating collection of patient survey instruments, and sending standardized patient charts to study investigators. The study received institutional review board approval.

\section{Standardized Patient Visits}

To address one of the study aims (reported elsewhere)_to compare physician behavior in response medically unexplained symptoms with behavior in response to straightforward patient symptoms - we created 2 contrasting standardized patient roles, both portraying patients with chest pain. The GERD role portrayed a 48 -year old patient (male or female) with typical symptoms of GERD. The medically unexplained symptoms role portrayed a moderately distressed patient (male or female) with multiple symptoms, including atypical chest pain. Each physician saw 2 standardized patients, 1 male and 1 female, and 1 of each illness condition randomized by order, illness condition, and patient sex. Each standardized patient visit was recorded using a digital, audio disk recorder with a high-quality microphone; all equipment was hidden inside a handbag or backpack.

Two days after the visit, a fax was sent to the physician to determine whether, when prompted, the physician was able to identify the standardized patient. The physician indicated at what point in the visit detection occurred, how realistic the patient portrayal was, and whether the physician altered any practice behavior because a standardized patient was suspected.

Visit length was calculated using the audio recording, excluding waiting time and any period of more than 1 minute during which the physician left the room. Audio recordings were analyzed using the Measure of Patient-Centered Communication (MPCC), ${ }^{23}$ a validated instrument based on a model of patientcentered communication, which includes the 3 major communication elements of patient-centered communication, measures physician responsiveness to patient concerns, and has been positively correlated with patient trust ${ }^{17}$ and patient perceptions of patientcenteredness. ${ }^{12} \mathrm{~A}$ full discussion of the measure can be found in the online-only Supplemental Appendix, available at http://www.annfammed.org/cgi/content/ full/3/5/415/DC1; theoretical considerations in measuring patient-centered communication are discussed in a recent publication. ${ }^{24}$

\section{Standardized Utilization Data}

To assess standardized health care services utilization, we derived standardized expenditures in discrete categories, diagnostic testing, hospital care, and total expenditures, from the MCO 1996-9 claims data. Details about the claims data have been published elsewhere. $^{25}$

\section{Analyses}

Data were analyzed at the patient level using Stata (Version 8.2, StataCorp, College Station, Tex). We used ordinary least squares regression to examine factors affecting the standardized expenditures in the categories described above; we used the logarithm of expenditures to adjust for the skewing of expenditure data. All analyses were adjusted for patient age, sex, Zip code-based socioeconomic status, ${ }^{25}$ year of enrollment, total years of enrollment, case-mix (a dummy variable for each ambulatory diagnostic group), physician specialty, and the nesting of patient observations within primary care physician. The key independent variable of interest, the physician's MPCC score, was expressed in terciles. Further details can be found in the Supplemental Appendix.

\section{RESULTS}

Of the 297 physicians with whom contact was attempted, 14 were later found to be ineligible (eg, planning to retire within 6 months), and 109 declined to participate (a loss of $42 \%$ of those originally eligible) in the process of recruiting the 100 study physicians. The most common reason for refusal was lack 
of time. As shown in Table 1, the sociodemographic, utilization, and clinical characteristics of patients in practices of enrolled and not enrolled physicians were similar. Of the 100 physicians, 93 completed both standardized patient visits. The rest completed only 1 standardized patient visit, and later moved out of the area or withdrew from the study for personal reasons. The mean total MPCC score for both cases was .50 with similar standard deviations and ranges (GERD case: standard deviation [SD] .09; range .25.74 ; medically unexplained symptoms case: SD .08; range $.25-.63)$; there was no statistically significantly difference between the scores. The correlation $(r)$ between the 2 MPCC scores was $0.39(P=.0001)$; the reliability, calculated using the Spearman-Brown prophecy formula, for the average of the 2 cases was .56. Subsequent analyses use the mean MPCC scores.

As displayed in Table 2, physicians with MPCC scores in the lowest tercile generated greater expenditures compared with other physicians. Compared with physicians in the combined middle and highest terciles, those with MPCC scores in the lowest tercile generated greater standardized diagnostic testing expenditures $(11.0 \%$ greater, $95 \%$ confidence interval $[\mathrm{CI}], 4.5 \%-17.8 \%)$ and total standardized expenditures (3.5\% greater, 95\% CI, 1.0\%-6.1\%). There was no significant $(P>.4)$ relationship between MPCC score and total expenditures with diagnostic expenditures subtracted out; that is, the effect of patient-centered communication on total standardized expenditures appears to reflect its effect on standardized diagnostic testing expenditures. There was no significant relationship between MPCC scores and standardized hospital expenditures.

Mean MPCC score was correlated with mean visit length $(r=0.36, P=$ .0002 ) for both roles. Mean visit lengths by MPCC tercile were 18.8 minutes (SD 5.2 minutes), 19.6 minutes (SD 3.3 minutes), and 22.8 minutes (SD 7.1 minutes), respectively, for the lowest to highest terciles. There were no relationships between visit length and costs when adjusted for MPCC scores; however, when adjusted for visit length, the relationship between MPCC scores and costs remained significant. These findings were adjusted for physician and patient demographics and illness burden as described in the Methods section.

In $80(40 \%)$ of the 198 visits, physicians were able to identify the standardized patient when prompted 2 days later. The most common reasons for detection were a closed physician practice $(n=19 ; 63 \%)$, physician notification by staff $(\mathrm{n}=10,33 \%)$, and poor acting by the standardized patient $(n=1,3 \%)$. For detected visits, mean physician rating of realism was 8.1 on a scale from 1 to 10 . Analyses were repeated excluding detected visits with realism scores below 7 , and repeated again adjusting for visit length and prompted suspicion that the patient was an standardized patient; these factors did not significantly affect the relationships between patient-centered communication and costs.

\section{Table 1. Characteristics of Patients and Physicians Enrolled and Not Enrolled in the Study}

\begin{tabular}{lcc}
\hline Characteristics & Not Enrolled & Enrolled \\
\hline Patient & & \\
Number & 483,094 & 121,806 \\
Age, years (SD) & $41.1(11.2)$ & $41.0(11.0)$ \\
Female sex, \% & 52.7 & 53.9 \\
Median income, \$ (SD)* & $36,874(10,160)$ & $37,830(10,683)$ \\
High-school graduation, \% (SD)* & $63.8(7.9)$ & $64.8(7.8)$ \\
Any visit to a physician, \% & 82.5 & 83.1 \\
Referred, \% & 25.6 & $3.07(1.12)$ \\
Years enrolled in the MCO, No. (SD) & $3.07(1.12)$ & $3.02(2.67)$ \\
ADGs, mean No. (SD) & $2.99(2.67)$ & $100^{\dagger}$ \\
Physician & & 47 \\
Number & 594 & $1218(758)$ \\
Specialty, family practice, \% & 24 & \\
Patients enrolled in the MCO, No. (SD) & $813(776)$ & \\
\hline SD = standard deviation; ADGs = ambulatory diagnostic groups; MCO = managed care organization. \\
* Socioeconomic variables derived from patient Zip code linked to 1990 census data. \\
$\begin{array}{l}\text { From the pool of 594 physicians, 297 were eligible for recruitment; family physicians were over- } \\
\text { sampled; cooperation rate was 33.7\%. }\end{array}$ & & \\
\hline
\end{tabular}

Table 2. The Relationship of Patient-Centered Communication to Adjusted Health Care Costs

\begin{tabular}{|c|c|c|c|}
\hline \multirow{2}{*}{$\begin{array}{l}\text { Standardized } \\
\text { Expenditure } \\
\text { Category }\end{array}$} & \multicolumn{3}{|c|}{ Tercile of MPCC Score } \\
\hline & $\begin{array}{l}\text { Lowest } \\
\text { Tercile* }\end{array}$ & $\begin{array}{l}\text { Middle Tercile }{ }^{\dagger} \\
(95 \% \mathrm{CI})\end{array}$ & $\begin{array}{l}\text { Highest Tercile }{ }^{\dagger} \\
(95 \% \mathrm{Cl})\end{array}$ \\
\hline Diagnostic testing costs & 100 & $90.3(84.3-96.9)$ & $89.6(83.9-95.6)$ \\
\hline Inpatient costs & 100 & $103.7(92.2-116.7)$ & $98.9(87.5-111.8)$ \\
\hline Total costs & 100 & $96.3(93.6-99.0)$ & $96.8(94.1-99.6)$ \\
\hline \multicolumn{4}{|c|}{$\begin{array}{l}\text { Note: Included are patients with at least some expenditures in each category. Adjusted percentage of } \\
\text { standardized expenditures presented as terciles of MPCC scores. Analyses adjust (from claims data) for } \\
\text { patient age, sex, Zip code-based socioeconomic status, ambulatory diagnostic groups, year, years of } \\
\text { enrollment, and physician specialty. }\end{array}$} \\
\hline \multicolumn{4}{|c|}{ MPCC = Measure of Patient-Centered Communication. } \\
\hline \multicolumn{4}{|c|}{ * Reference value. } \\
\hline$\dagger$ As percentage of lowest te & & & \\
\hline
\end{tabular}




\section{DISCUSSION}

This study suggests that physicians with a more patient-centered communication style tend to have fewer diagnostic testing expenditures. Total standardized expenditures were also less for these physicians, largely reflecting the relationship between patient-centered communication and diagnostic testing.

This study adds to previous research on patientcentered communication and health care costs by bringing several specific strengths. First, the measures were not all derived solely from the patient visit; we used independent sources of data to avoid contamination of one measure by another. Second, we used actual expenditures, not just a count of tests generated only by the patients studied. Third, the relationship was based on observational measures of patient-centered communication rather than patient survey reports which are subject to unmeasured patient confounding. ${ }^{14,24}$ Fourth, despite their drawbacks, standardized patients greatly reduce the variation typically observed using real patients, avoiding some of the confounding encountered in naturalistic observation studies.

Finally, we examined standardized inpatient expenditures as a control condition. While primary care physicians have a substantial degree of direct control over outpatient diagnostic testing utilization, they have relatively little impact on the standardized expenditures of hospitalizations, which are based on diagnostic related groups and are affected mostly by patient casemix. The finding that inpatient costs were not affected by patient-centered communication suggests that inadequate adjustment for patient characteristics (particularly case-mix) does not explain relationship between MPCC scores and expenditures.

The mechanisms for a relationship between patientcentered communication and diagnostic testing have not been explored and should be incorporated into future randomized trials of interventions to improve patient-centered communication. ${ }^{26}$ We have shown a relationship between trust and patient-centered communication ${ }^{17}$; patient-physician relationships characterized by a higher level of trust may result in less perceived or real pressure on physicians to order tests. ${ }^{18}$ Other possible mediators of the drive to test include patient factors (symptoms, anxiety, trust, requests, autonomy support, self-efficacy) and physician factors (tolerance of uncertainty, personality). ${ }^{27-34}$ Further studies should examine whether patient-centered communication is associated with a reduction in inappropriate testing, appropriate testing, or both.

We noted that visit length tended to increase with increased MPCC scores, but that MPCC, not visit length, was associated with costs. Longer visits are likely associated with improved quality of care in several domains, including prevention, prescribing, response to emotional distress, and information exchange. ${ }^{35-37}$ Further research is also needed to determine the causal relationships among patient-centered communication, visit length, and outcomes-for example, whether longer visits are a necessary but not sufficient condition for patient-centered communication, or whether shortening visits interferes with patient-centered communication and results in greater overall costs. Given current incentives to see more patients in less time, physicians using a more patient-centered consultation style may be at a financial disadvantage if their longer visits reduce the number of patients they can see, or if they take additional time without receiving additional compensation. These physicians may be at greater risk for stress, fatigue, and burnout, which in turn can negatively affect quality of care. Educational programs should develop means for training in patient-centered communication skills while emphasizing time management.

\section{Study Limitations}

The difficulties of studying the relationship between patient-centered communication and costs should not be underestimated; our results are subject to multiple interpretations for several reasons. Stable measures of physician style, extrapolating from our calculations, would require 6 standardized patient visits; however, physicians would not have participated had that been our protocol. Using real patients to measure patient-centered communication invites unmeasured confounding. The calculation of health care costs is an inexact science.

The observational and cross-sectional nature of the data precludes making causal interpretations. The mechanisms by which observed differences in physician communication might reduce diagnostic testing or increase visit duration are uncertain. Also, it is unclear whether the reduction in testing affected the quality of care.

Patient-centered communication is an aggregation of loosely related skills, such as eliciting the patient's perspective on the problem, inquiring into the psychosocial context, and encouraging patient participation in decisions. ${ }^{24}$ Although MPCC components correspond to some of these skills, the case-to-case consistency of physician behavior and the interrater reliability of the components are insufficient to indicate which skills or behaviors are most directly related to health care costs. Although the MPCC shows good interrater reliability for individual standardized patient visits, the ability to detect a physician's overall style is limited when measured with only 2 visits. Thus, some physicians may be misclassified. This bias is likely to result in underestimation of the true relationship between patient-centered communication and diagnostic testing expenditures. It is possible that unmeasured confounding explains both 
higher levels of observed patient-centered communication and fewer diagnostic testing expenditures. For example, some physicians may systematically attract patients who induce more patient-centered behaviors in their physicians while also demanding fewer tests.

Using standardized patients results in advantages and difficulties. The choice of the standardized patient roles may have selected for certain specific types of physician behavior. Additional visits would likely have increased reliability, but would have made physician recruitment and retention difficult. Even so, we exceeded the standards of nearly all other published studies using unannounced standardized patients, which have used just 1 standardized patient visit per physician. Furthermore, physicians' behavior with a new patient might not predict their subsequent behavior as the relationship develops with time. ${ }^{38}$ To have used audio-recorded real patient visits would introduce Hawthorne effects, as physicians may have become more accommodating to patient requests.

Detection of standardized patients did not affect the results we report. There appears to be an inverse relationship between timing of the inquiry and the reported detection rate. We chose to inform physicians 2 days after the visit as a courtesy so they would not need to pursue the patient further. The proximity of the prompt to the standardized patient visit, however, allowed physicians to choose from a small pool of recent patients whom they might recall. Data from the same physician pool from a more recent study in which detection notification was requested 10 working days after the standardized patient visit resulted in a meaningful detection rate of $12.8 \% .{ }^{39}$ Other studies that report detection rates as low as $2 \%$ simply asked the physicians to contact study personnel if they suspected they had seen an standardized patient and were never prompted. ${ }^{40}$

Unmeasured pharmacy expenditures may have compensated for the savings realized in diagnostic testing That is, physicians scoring higher on the MPCC may have tended to prescribe empirically rather than base prescribing on diagnostic test results. Pharmacy data in the MCO database were incomplete and inadequate for analysis.

The results apply only to those physicians selected into the study sample. While the patients of enrolled and not enrolled physicians appear to be similar, participating physicians are likely to exhibit some important differences from others in the community. Because other recruitment methods would not have provided an adequate sample size, physicians were recruited by peers; they also agreed to participate in a relatively intrusive study. Generalization to patients with different insurance plans (or no insurance), and beyond primary care physicians in the Rochester, NY, area remains unproved.
Patient-centered communication represents an attempt to balance two imperatives in the clinical encounter: the need to arrive at a diagnosis and treatment plan, and the need to understand patients and involve them in care. Our findings should reduce fears that encouraging patient-centered communication would necessarily drive up health care costs. Although we found that patient-centered communication is associated with fewer diagnostic testing expenditures, a patient-centered approach should not be implemented solely for economic reasons. Patients should also perceive their care as better, and health outcomes should be improved. Although the evidence for the former is strong, more research is needed to assess the effect of patient-centered communication training on health outcomes. Randomized trials should study the effects of patient-centered communication on health care costs to confirm our observational finding. The possibility that primary care physicians are penalized for their patientcentered communication by increasing visit length without additional compensation should also be investigated further, as it might discourage physicians from practicing in a patient-centered manner.

To read or post commentaries in response to this article, see it online at http://www.annfammed.org/cgi/content/full/3/5/415.

Key words: Communication; health care economics; health care delivery; physician-patient relations; standardized patients; diagnostic tests, routine; health expenditures; evaluation studies

Submitted January 3, 2005; submitted, revised, May 6, 2005; accepted May 9, 2005.

Funding support: Patient Centered Care and Health Care Costs, AHRQ R01-HS1610-01A1, Ronald M. Epstein, Principal Investigator; Socioeconomic Disparities and Managed Care Utilization, AHRQ R01 HS0996301A1, Peter Franks, Principal Investigator.

Acknowledgments: The authors thank Patricia Carney, RN, PhD, for her help developing standardized patient training protocols; Moira Stewart, $\mathrm{PhD}$, and Judith Belle Brown, PhD, for their expertise in coding of audio recordings; and Richard Kravitz, MD, MSPH, for his careful review of the manuscript. William Bayer, MD, Marc Berliant, MD, Phillip Bonanni, MD, Paul Frame, MD, Diane Morse, MD, Timothy Quill, MD and Geoffrey Williams, MD, PhD, helped recruit physicians for the study. Judi Lardner assisted with manuscript preparation and references.

\section{References}

1. Mead N, Bower P. Patient-centredness: a conceptual framework and review of the empirical literature. Soc Sci Med. 2000;51:1087-1110.

2. Stewart M, Brown JB, Weston WW et al, eds. Patient-Centered Medicine: Transforming the Clinical Method. Thousand Oaks, Calif: Sage Publications; 1995.

3. McWhinney IR. Why we need a new clinical method. In: Stewart M, Brown JB, Weston WW, et al, eds. Patient-Centred Medicine: Transforming the Clinical Method. Thousand Oaks, Calif: Sage Publications; 1995:1-18 
4. Mead N, Bower P, Hann M. The impact of general practitioners' patient-centredness on patients' post-consultation satisfaction and enablement. Soc Sci Med. 2002;55:283-299.

5. Stewart M, Brown JB, Boon H, et al. Evidence on patient-doctor communication. Cancer Prev Control. 1999;3:25-30.

6. Mead N, Bower P. Patient-centred consultations and outcomes in primary care: a review of the literature. Patient Educ Couns. 2002; 48:51-61.

7. Kaplan SH, Greenfield S, Ware JE, Jr. Assessing the effects of physician-patient interactions on the outcomes of chronic disease. Med Care. 1989;27:S110-127.

8. Michie S, Miles J, Weinman J. Patient-centredness in chronic illness: what is it and does it matter? Patient Educ Couns. 2003;51:197-206.

9. Roter DL, Stewart M, Putnam SM, et al. Communication patterns of primary care physicians. JAMA. 1997;277:350-356.

10. Swenson SL, Buell S, Zettler $P$, et al. Patient-centered communication: do patients really prefer it? J Gen Intern Med. 2004;19:1069-1079.

11. Krupat E, Bell RA, Kravitz RL, Thom D, Azari R. When physicians and patients think alike: patient-centered beliefs and their impact on satis faction and trust. J Fam Pract. 2001;50:1057-1062.

12. Stewart M, Brown JB, Donner A, et al. The impact of patient-centered care on outcomes. J Fam Pract. 2000;49:796-804.

13. Bertakis KD, Azari R, Callahan EJ, Helms LJ, Robbins JA. The impact of physician practice style on medical charges. J Fam Pract. 1999:48:31-36.

14. Franks P, Fiscella K, Shields CG, et al. Are patients' ratings of their physicians related to health outcomes? Ann Fam Med. 2005;3:229-234.

15. Hall JA, Roter DL, Milburn MA, Daltroy LH. Patients' health as a pre dictor of physician and patient behavior in medical visits. A synthesis of four studies. Med Care. 1996;34:1205-1218.

16. Street RL, Jr., Krupat E, Bell RA, Kravitz RL, Haidet P. Beliefs about control in the physician-patient relationship: effect on communication in medical encounters. J Gen Intern Med. 2003;18:609-616.

17. Fiscella $K$, Meldrum $S$, Franks $P$, et al. Patient trust: is it related to patient-centered behavior of primary care physicians? Med Care. 2004:42:1049-1055.

18. Hillman AL. Mediators of patient trust. JAMA. 1998;280:1703-1704.

19. Epstein RM, Quill TE, McWhinney IR. Somatization reconsidered: incorporating the patient's experience of illness. Arch Intern Med. 1999;159:215-222.

20. Deyo RA, Diehl AK. Patient satisfaction with medical care for lowback pain. Spine. 1986;11:28-30.

21. McLeod PJ, Tamblyn RM, Gayton D, et al. Use of standardized patients to assess between-physician variations in resource utilization. JAMA. 1997;278:1164-1168.

22. Peabody JW, Luck J, Glassman P, Dresselhaus TR, Lee M. Comparison of vignettes, standardized patients, and chart abstraction: a prospective validation study of 3 methods for measuring quality. JAMA. 2000;283:1715-1722.
23. Brown J, Stewart M, Ryan BL. Assessing Communication Between Patients and Physicians: The Measure of Patient-Centered Communication (MPCC). London, Ontario Canada: Thames Valley Family Practice Research Unit and Centre for Studies in Family Medicine; 2001. Working Paper Series, Paper \# 95-2, Second Edition.

24. Epstein RM, Franks P, Fiscella K. Measuring patient-centered communication in physician-patient consultations: theoretical and practical issues. Soc Sci Med. 2005:61:1516-1528.

25. Franks $P$, Fiscella $K$, Beckett $L$, et al. Effects of patient and physician practice socioeconomic status on the health care of privately insured managed care patients. Med Care. 2003;41:842-852.

26. Lewin SA, Skea ZC, Entwistle V, Dick J, Zwarenstein M. Interventions for Providers to Promote a Patient-Centered Approach in Clinical Consultations. Oxford: Update Software; 2001.

27. Kassirer JP. Our stubborn quest for diagnostic certainty. A cause of excessive testing. N Engl J Med. 1989;320:1489-1491.

28. Mold JW, Stein HF. The cascade effect in the clinical care of patients. N Engl J Med. 1986;314:512-514

29. Allison JJ, Kiefe Cl, Cook EF, et al. The association of physician attitudes about uncertainty and risk taking with resource use in a Medicare HMO. Med Decis Making. 1998;18:320-329.

30. Lillrank A. Back pain and the resolution of diagnostic uncertainty in illness narratives. Soc Sci Med. 2003;57:1045-1054.

31. Sullivan M. The new subjective medicine: taking the patient's point of view on health care and health. Soc Sci Med. 2003;56:1595-1604

32. Mancuso CA, Rincon M, McCulloch CE, Charlson ME. Self-efficacy, depressive symptoms, and patients' expectations predict outcomes in asthma. Med Care. 2001:39:1326-1338.

33. Bell RA, Kravitz RL, Thom D, Krupat E, Azari R. Unsaid but not forgotten: patients' unvoiced desires in office visits. Arch Intern Med. 2001:161:1977-1984.

34. Roter DL, Hall JA, Kern DE, et al. Improving physicians' interviewing skills and reducing patients' emotional distress. A randomized clinica trial. Arch Intern Med. 1995:155:1877-1884.

35. Tamblyn R, Berkson L, Dauphinee WD, et al. Unnecessary prescribing of NSAIDs and the management of NSAID-related gastropathy in medical practice. Ann Intern Med. 1997:127:429-438.

36. Dugdale DC, Epstein R, Pantilat SZ. Time and the patient-physician relationship. J Gen Intern Med. 1999;14 Suppl 1:S34-40.

37. Flocke SA, Miller WL, Crabtree BF. Relationships between physician practice style, patient satisfaction, and attributes of primary care. J Fam Pract. 2002;51:835-840.

38. Tamblyn RM, Abrahamowicz M, Berkson L, et al. First-visit bias in the measurement of clinical competence with standardized patients. Acad Med. 1992;67:S22-24

39. Kravitz RL, Epstein RM, Feldman MD, et al. Influence of patients' requests for direct-to-consumer advertised antidepressants: a randomized controlled trial. JAMA. 2005;293:1995-2002.

40. Beullens J, Rethans JJ, Goedhuys J, Buntinx F. The use of standardized patients in research in general practice. Fam Pract. 1997;14:58-62. 